ORIGITIL PIPERS

\title{
A comparative study of anxiety among HIV seropositive individuals, cancer patients and individuals from the normative population
}

\author{
Mwiya Liamunga Imasiku \\ email:imasikumwiya@gmail.com \\ University of Zambia, Psychology Department \\ Lusaka, Zambia
}

\begin{abstract}
Excessive anxiety contributes to a sense of helplessness in which a person feels little control over the present or future and continues maladaptive behaviour patterns. In view of the negative influence of long standing anxiety, the present study attempts to find an answer regarding the possible differences between the prevalence and impact of anxiety in HIV seropositive individuals, cancer patients and individuals from the normative population. Anxiety is a major health harzard in HIV seropositive individuals. This is so because it is probably one of the factors responsible for the quick progression of their HIV seropositive status to AIDS.
\end{abstract}

Method: The sample consisted of 180 subjects. Half of these individuals (90) came from Zambia and the remaining 90 came from India. Out of each group of 90 individuals, 30 were HIV seropositive individuals, 30 were HIV negative but with cancer and 30 were individuals from the normative population (having none of the above two mentioned conditions i.e. HIV or Cancer). In Zambia, the sample was drawn from the University Teaching Hospital (UTH), Kara Counseling - Hope house, Mother Theresa Hospice and Network of Zambian people living with HIV $(\mathrm{NZP}+)$. In India the sample was drawn from Snehandan, Karnataka network for people living with HIV (KNP+), and Kidwai Hospital.

The technique of assessment used was the Symptoms Questionnaire developed ${ }^{1}$ used to assess anxiety and physical illness behavior (somatic symptoms). The data obtained was analyzed using ' $t$ ' tests and analysis of covariance. In the present investigation an attempt

Keywords: Anxiety; HIV seropositive was made to explore the intensity of anxiety in HIV+ individuals, Cancer patients and individuals from the normative population.

Conclusion: The findings of the present study reveal that HIV+ individuals and cancer patients have higher levels of anxiety than individuals from the normative population. Anxiety is also found to be positively correlated with physical illness behavior. This indicates that high level of anxiety and physical illness behavior seem to co- exist. It's therefore likely that a high level of anxiety is a core factor that might be responsible for the quick progression of HIV infection into AIDS.

\section{INTRODUCTION}

The study of anxiety among those with serious chronic medical conditions has emerged as an important area of research and public health interest. The World Heath Organization has given a comprehensive definition of Health. It states that health is not just being free from physical symptoms; rather it is a state of complete physical, mental and social well-being ${ }^{2}$. There are many researchers trying to understand the interaction between mood disturbances like anxiety. The term anxiety refers to the unpleasant sense of apprehension that accompanies physical symptoms such as sweaty palms, shallow breathing, rapid heart rate, general nervousness and feelings of stress. Many people often perceive anxiety to be negative, anxiety is not necessarily detrimental. It can be helpful when it becomes the impetus for making behaviour changes to reduce future risk to re-exposures, to discontinue practices that would permit illness transmission, and to adopt more healthy styles of living. However, 
anxiety levels are harmful when they interfere with the client's comfort and effectiveness in daily life and create subjective misery. When anxiety persists overtime, the body weakens and begins to break under pressure. Anxiety in an individual, according to studies ${ }^{3}$ decreases lymphocyte counts and functions. Anxiety can produce ulcers, headaches, rashes, backaches, skin rashes and a variety of other physical problems. This is the beginning of psychosomatic (psychologically caused) illnesses. Anxiety is one of the most common reactions of many individuals upon receiving a diagnosis that they are infected with HIV.

\section{Effects of anxiety in HIV+ individuals}

Dixon in his study revealed that sheer freight can produce the entire symptoms of early infection ${ }^{4}$. The study cited an instance of a doctor in New York who was convinced that he had AIDS after a minor accident. He worried, became depressed and tired, stopped eating and lost weight. He had diarrhea, produced a temperature, and finally developed rashes typical of early infection. Every test was negative even the antibody test. He then became convinced that he was in the fewer than one out of a hundred who never produce a positive test. When this man was followed up. He did not have AIDS or any other early signs.

Anxiety affects the well-being of HIV+ individuals when they preoccupy their minds with the possibility of future helplessness or dependency. There may even be awful feelings of abrupt and complete loss of control over one's life. They often have profound feelings of grief about the loss they have experienced or are anticipating. As the need for care increases, a sense of loss of privacy and control over life is also experienced. This feared dependency might be physical as the person imagines future scenarios involving eventual depletion of savings. Loss of a job means loss of income which in turn means loss of physical attractiveness and sexual relationships, status in society, financial stability, independence and lifestyle.

The disastrous psychological effect of having one's mind preoccupied with the possibility of future helplessness or dependence include: mood swings and increased anxiety.

Grant and Atkinson through their study on psychiatric aspects of Acquired Immune Deficiency Syndrome revealed that over 20 per cent of seropositive individuals have been reported to experience anxiety symptoms at least once in a month, compared with negligible rates in the community among low-risk controls ${ }^{5}$.

The current study focuses on HIV seropositive men, cancer patients and an HIV (-) control group. The study addressed the following questions:

1. How do current rates of anxiety symptoms among HIV seropositive men compare with cancer patients and individuals from the normative population (HIV-control group)

2. What is the relationship between anxiety symptoms and measures of physical symptoms

3. Do anxiety symptoms change over time, and if so, are men whose immunologic markers improved or worsened over 2 years experiencing a concomitant change in anxiety

\section{METHODOLOGY}

The present study was conducted in only one phase which involved administering the symptoms questionnaire to determine levels of anxiety and somatic symptoms of the subjects. Before the study commenced, Ethics Committee approval was obtained. A multiple group design was used to assess the intensity and impact of anxiety on HIV seropositive individuals, cancer patients and individuals from the normative population.

\section{Objectives of the study}

- To find out the impact of anxiety on physical illness behavior among HIV seropositive individuals.

- To find an answer regarding the possible differences between the intensity of anxiety between HIV+ individuals, cancer patients and individuals from the normative population with regard to their health status.

\section{Hypotheses}

The foregoing theoretical analysis led to the formation of the following hypothesis.

- Diagnosis will influence anxiety.

- Physical illness behavior is positively correlated to anxiety. 


\section{Operational definition}

- Anxiety is an unpleasant emotional state marked by worry, apprehension and tension ${ }^{6}$

- Somatic symptoms in the present study are the indicators of physical illnesses such as head pains, cramps, muscle pains, upset bowels, nausea, weak arms and legs and not feeling healthy generally.

- HIV seropositivity is development of neutralizing antibodies in individuals who have been exposed to the human immunodeficiency virus; it is state in which the condition of an HIV infected individual has not yet progressed to AIDS.

- Physical illness behaviour implies somatic symptoms which in the present study are indicators of physical illnesses such as head pains, cramps, muscle pains, upset bowels, nausea, weak arms and legs.

\section{Sample}

Subjects were 180 men (90 HIV seropositive individuals, 90 cancer patients, and 90 HIV-) who participated in a prospective study with semiannual assessments examining psychological wellbeing factors related to adjustment to HIV infection. The focus of recruitment was on HIV seropositive individuals but all subjects were assessed at the same time. Initially, the 180 subjects were classified into three groups: HIV + men were classified as (1) asymptomatic with a CD4 cell count 200-499, (2) no AIDS diagnosis, and (3) those patients with cancer. The third group consisted of 90 HIV negative men assessed only at baseline. Flyers seeking male volunteers for the study about coping with HIV infection were posted at HIV community-based organizations. Exclusion criteria included 1) being too ill to come to the assessment centre 2) being a current intravenous drug user 3 ) inability to speak English 4) previous history of psychiatric or neurological consultations and mental deficiencies 5) unwilliness to be part of the study 6) exposure to a similar study before.

\section{Inclusion Criteria for Selection}

- Males between the ages of 18 and 50 years.

- HIV seropositive individuals diagnosed in the first one year

- Males with an educational background/status of at least class or grade ten.
Sampling technique: The sampling technique which was used in the research was stratified sampling because the population was categorized on the basis of nationality (Zambians and Indians) and on the basis of diagnosis (Cancer patients, individuals from the normative population and HIV seropositive individuals).

The criteria used to select these institutions depended on the availability of the required respondents in those institutions.

The sample for the present study was drawn from the following Zambian institutions-
a) KARA Counseling Centre (KCC)
b) Net work for People Living with HIV in Zambia (NPZ)
c) University Teaching Hospital (UTH)
d) Mother Theresa Hospice

From India the sample for the present study was drawn from the following Indian institutions:
a) Snehadhan
b) Karnataka Network for people Living with HIV $(\mathrm{KNP}+)$
c) Kidwai Cancer Hospital
d) White field Cancer centre.

\section{Description of sample}

Sample for phase I: The sample that was selected for the study consisted of 180 subjects. Half of these individuals (90) came from Zambia and the remaining 90 came from India. Out of each group of 90 individuals, 30 were HIV seropositive individuals, 30 were HIV negative but with cancer and 30 were individuals from the normative population (having none of the above two mentioned conditions i.e. HIV or Cancer). The sample was chosen as per the following criteria:

\section{Sample Characteristics}

Table 1: The sample distribution of the study

\begin{tabular}{|c|c|c|c|c|}
\hline & $\begin{array}{c}\text { HIV } \\
\text { seropositive } \\
\text { Individuals }\end{array}$ & $\begin{array}{c}\text { Cancer } \\
\text { patients }\end{array}$ & $\begin{array}{c}\text { Individuals from } \\
\text { the normative } \\
\text { population }\end{array}$ & Total \\
\hline Zambia & 30 & 30 & 30 & 90 \\
\hline India & 30 & 30 & 30 & 90 \\
\hline & 60 & 60 & 60 & 180 \\
\hline
\end{tabular}


The first stage consisted of classification of the respondents into groups based on their diagnosis. The sample size in this stage of study consisted of 180 subjects- drawn from different organizations/ institutions in Zambia and India.

The tables 2-4 give the details of the sample.

Table 2: Distribution of HIV+, Cancer and Normal individuals from Zambian institutions Institution

\begin{tabular}{|l|l|l|l|llll|}
\hline \multicolumn{1}{|c|}{ Institution } & \multicolumn{2}{|c|}{ HIV(+) } & \multicolumn{3}{c|}{$\begin{array}{c}\text { Cancer } \\
\text { patients }\end{array}$} & Normal \\
& & \multicolumn{1}{|c|}{ Freq } & $\%$ & Freq & $\%$ & Freq & $\%$ \\
\hline University Teaching Hospital (UTH) & 0 & 0 & 21 & 70 & 0 & 0 \\
\hline KARA Counseling Centre & 10 & 33.3 & 3 & 10 & 0 & 0 \\
\hline Mother Theresa Hospice & 0 & 0 & 6 & 20 & 0 & 0 \\
\hline $\begin{array}{l}\text { Network of Zambian people with } \\
\text { HIV/AIDS (NZP+) }\end{array}$ & 16 & 53.3 & 0 & 0 & 0 & 0 \\
\hline Miscellaneous & 4 & 13.3 & 0 & 0 & 30 & 100 \\
\hline \multicolumn{1}{|c|}{ Total } & $\mathbf{3 0}$ & $\mathbf{1 0 0}$ & $\mathbf{3 0}$ & $\mathbf{1 0 0}$ & $\mathbf{3 0}$ & $\mathbf{1 0 0}$ \\
\hline
\end{tabular}

Table 2 indicates the distribution of HIV seropositive individuals, Cancer patients and Normal individuals from Zambian institutions. These included University Teaching Hospital, KARA Counseling center, Mother Theresa Hospice, and Network for people living with HIV.

Table 3: Distribution of HIV+, Cancer and Normals from Indian institutions

\begin{tabular}{|c|c|c|c|c|c|c|}
\hline Institution & \multicolumn{2}{|c|}{ HIV(+) } & \multicolumn{2}{c|}{ Cancer patients } & \multicolumn{2}{c|}{ Normal } \\
\hline Kidwai & Freq & $\%$ & Freq & $\%$ & Freq & $\%$ \\
\hline Snehadhan & 0 & 0 & 30 & 100 & 0 & 0 \\
\hline KNP+ & 8 & 26.6 & 0 & 0 & 0 & 0 \\
\hline Miscellaneous & 16 & 53.3 & 0 & 0 & 0 & 0 \\
\hline Total & 6 & 20 & 0 & 0 & 30 & 100 \\
\hline & $\mathbf{3 0}$ & $\mathbf{1 0 0}$ & $\mathbf{3 0}$ & $\mathbf{1 0 0}$ & $\mathbf{3 0}$ & $\mathbf{1 0 0}$ \\
\hline
\end{tabular}

Table 3 indicates the distribution of HIV seropositive individuals, Cancer patients and Normal individuals from Indian institutions. These institutions are as follows: Kidwai, Snehadhan, Karnataka network for people living with HIV
Table 4: Age distribution of the respondents from Zambia and India

\begin{tabular}{|c|c|c|c|c|c|c|c|c|c|}
\hline \multirow{3}{*}{$\begin{array}{l}\text { Age } \\
20-29\end{array}$} & \multicolumn{3}{|l|}{ ZAMBIA } & \multicolumn{6}{|c|}{ INDIA } \\
\hline & HIV(+) & $\begin{array}{l}\text { Cancer } \\
\text { patients }\end{array}$ & Normal & \multicolumn{2}{|c|}{ HIV $(+)$} & \multicolumn{2}{|c|}{$\begin{array}{l}\text { Cancer } \\
\text { patients }\end{array}$} & \multicolumn{2}{|c|}{ Normal } \\
\hline & Freq & Freq \% & Freq \% & Freq & $\%$ & Freq & $\%$ & Freq & $\%$ \\
\hline $30-39$ & 43.3 & 36.6 & $14 \quad 46.6$ & 6 & 20 & 14 & 46.6 & 20 & 66.7 \\
\hline $40-50$ & 36.6 & 33.3 & $12 \quad 40$ & 19 & 63.3 & 5 & 16.6 & 8 & 26.6 \\
\hline Mean & 20 & 30 & 13.3 & 5 & 16.6 & 11 & 36.6 & 2 & 6.6 \\
\hline \multirow[t]{2}{*}{ S.D } & 33.1 & 35.1 & 32.6 & 34.9 & & 32.9 & & 26.5 & \\
\hline & 7.1 & 8.52 & 7.27 & 6.19 & & 10.8 & & 7.12 & \\
\hline
\end{tabular}

Table 4 indicates the age distribution of the sample. The reason for selecting this age group is because it constitutes both the HIV prevalence [the percentage of persons ages 15 to 49 who are HIV infected] and HIV incidence [the percentage of uninfected 15 to 49 year olds who become newly infected each year]

Table 5: Religion of the sample from Zambia and India

\begin{tabular}{|c|c|c|c|c|c|c|c|c|c|c|c|c|}
\hline Nation & \multicolumn{6}{|c|}{ ZAMBIA } & \multicolumn{6}{|c|}{ INDIA } \\
\hline \multirow[t]{2}{*}{ Religion } & \multicolumn{2}{|c|}{ HIV(+) } & \multicolumn{2}{|c|}{$\begin{array}{l}\text { Cancer } \\
\text { patients }\end{array}$} & \multicolumn{2}{|c|}{ Normal } & \multicolumn{2}{|c|}{ 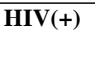 } & \multicolumn{2}{|c|}{$\begin{array}{l}\text { Cancer } \\
\text { patients }\end{array}$} & \multicolumn{2}{|c|}{ Normal } \\
\hline & Freq & $\%$ & Freq & $\%$ & Fre & $\%$ & Freq & $\%$ & Freq & $\%$ & Frec & \\
\hline Christians & 29 & 96.6 & 26 & 86.6 & 30 & 100 & 2 & 6.6 & 1 & 3.3 & 10 & 33.3 \\
\hline Hindus & 0 & 0 & 0 & 0 & 0 & 0 & 25 & 83.3 & 26 & 86.6 & 19 & 63.3 \\
\hline Moslems & 0 & 0 & 0 & 0 & 0 & 0 & 3 & 10 & 2 & 6.6 & 1 & 3.3 \\
\hline Others & 1 & 3.3 & 4 & 13.3 & 0 & 0 & 0 & 0 & 1 & 3.3 & 0 & 0 \\
\hline Total & 30 & 100 & 30 & 100 & 30 & 100 & 30 & 100 & 30 & 100 & 30 & 100 \\
\hline
\end{tabular}

The data in table 5 shows the distribution of religion in the sample studied from Zambia and India. The majority of the respondents from Zambia in all the three categories HIV+, Cancer, and Normal are Christians. On the other hand, in the sample studied from India, the majority of the respondents in all the three categories are Hindus. These results are as per the statistics in the respective countries.

\section{Table 6 Family income of respondents from Zambia and India}

To check whether the samples in terms of annual family income are comparable, chi square analysis was done and the table 10 gives the results

\begin{tabular}{|c|c|c|c|c|c|c|c|c|}
\hline & \multicolumn{4}{|c|}{ India } & \multicolumn{4}{|c|}{ Zambia } \\
\hline $\begin{array}{c}\text { Family annual } \\
\text { income }\end{array}$ & HIV(+) & $\begin{array}{l}\text { Cancer } \\
\text { patients }\end{array}$ & Normal & & HIV $(+)$ & $\begin{array}{c}\text { Cancer } \\
\text { patients }\end{array}$ & Normal & \\
\hline $\begin{array}{c}\text { Below } 219 \text { US } \\
\text { Dollars }\end{array}$ & & & & & & & & \\
\hline $\begin{array}{c}\text { Dollars } \\
\text { Between } 219 \text { US }\end{array}$ & 7 & 12 & 5 & 24 & 9 & 7 & 16 & 32 \\
\hline Between 219 US & 13 & 13 & 14 & 40 & 13 & 13 & 7 & 33 \\
\hline $\begin{array}{c}\text { Dollars \& } 879 \text { US } \\
\text { Dollars } \\
\end{array}$ & & & & & & & & \\
\hline Between 879 US & 10 & 5 & 11 & 26 & 8 & 10 & 7 & 25 \\
\hline Dollars and 1,319 & & & & & & & & \\
\hline US Dollars & 30 & 30 & 30 & 90 & 30 & 30 & 30 & 90 \\
\hline Total & & $\begin{array}{r}\mathrm{X}^{2}=3.20 \\
\text { significan }\end{array}$ & $\begin{array}{l}0 \mathrm{Not} \\
\mathrm{tDF}=2\end{array}$ & & & $\begin{array}{l}\mathrm{X}^{2}=1.86 \\
\text { significan }\end{array}$ & $\begin{array}{l}\mathrm{Not} \\
\mathrm{tDF}=2\end{array}$ & \\
\hline
\end{tabular}


Since all the above $\mathrm{X}^{2}$ values are non-significant, we can therefore conclude that the groups are homogenous in terms of the significant demographic variables of education and annual family income. The rationale for selecting a homogeneous group in terms of social-economic status, (respondents who are above poverty line) is because, poverty has been reported to play a significant role in not only the spread of HIV but also in expediting the progression of HIV into AIDS ${ }^{7}$

\section{PROCEDURE}

Subjects were seen semiannually for assessment including clinical psychological interviews as well as self-reports. The study used data from the first three study visits beginning in September 2000 and through April 2003. Interviews and assessments personnel included a clinical psychologist, a physician in HIV who collected medical information and performed blood tests. All subjects gave written informed consent and were paid transport money.

\section{Assessment Tools}

\section{Consent form}

A consent form was developed for the present study. This is a written consent form which elicited information that the respondents have agreed to be part of the study. Prior to the administration of all parameters, the willingness of the subjects was ascertained and they were made to sign a consent form.

\section{Information schedule}

This information schedule, which was semistructured, was specially developed to collect data relevant for the study and ascertain certain socio-demographic details.

III. Markers of HIV Illness Stage

Laboratory. Quest laboratories performed assays to determine number and percent of CD4+ T-cells.

IV. Symptoms Questionnaire (Kellner, 1986). This is a checklist of symptoms commonly associated anxiety and physical illness behavior was used. Symptoms were scored as present or not over the past two weeks. This questionnaire was used to assess anxiety and physical illness behavior (somatic symptoms). To obtain the Anxiety, and Somatic score, the scores obtained for each scale are added. A higher scale score indicates more inclination in that sub scale.

\section{Statistical Analysis}

Chi-square analysis was used to compare the three groups to ensure that they were homogenous. When appropriate, Pearson correlations to assess the relationship among diagnoses, continuous anxiety measures and physical illness behavior. Repeated measures analysis of variance (Two way ANOVAs) assessed changes in continuous anxiety variables overtime. T tests were also carried out.

\section{RESULTS}

The comparison of the three groups: In order to test hypotheses, the scores of the three groups on anxiety variable of the symptoms questionnaire are subjected to quantitative analysis. The results of the analysis are summarized in the table below-

\section{Table 7: Educational status of respondents from Zambia}

To check whether the samples are comparable in terms of education, chi square analysis was done and the table below gives the results

\begin{tabular}{|l|l|l|l|l|l|l|l|l|}
\hline Nation & \multicolumn{3}{|l|}{ India } & \multicolumn{3}{l|}{ Zambia } \\
\hline Education & HIV(+) & $\begin{array}{l}\text { Cancer } \\
\text { patients }\end{array}$ & Normal & & HIV(+) & $\begin{array}{l}\text { Cancer } \\
\text { patients }\end{array}$ & Normal & \\
\hline $\begin{array}{l}\text { Higher/Senior } \\
\text { Secondary } \\
\text { School Level }\end{array}$ & 21 & 16 & 6 & 43 & 15 & 14 & 9 & 38 \\
\hline Under graduate & 9 & 14 & 24 & 47 & 15 & 16 & 21 & 52 \\
\hline Total & 30 & 30 & 30 & 90 & 30 & 30 & 30 & 90 \\
\hline & $\begin{array}{l}\mathrm{X}^{2}=0.178 \text { Not significant } \\
\mathrm{DF}=1\end{array}$ & $\begin{array}{l}\mathrm{X}^{2}=0.44 \text { Not significant } \\
\mathrm{DF}=1\end{array}$ \\
\hline
\end{tabular}

Since all the above $\mathrm{X}^{2}$ values for education are not significant, we can therefore conclude that the 3 groups of $\mathrm{HIV}+$, cancer and normals from Zambia and India are homogenous in terms of the significant demographic variable of educational occupation.

Table 8: Results of the symptoms questionnaire variable 'anxiety' in HIV seropositive, cancer patients and normal individuals from Zambia and India.

\begin{tabular}{|c|c|c|c|c|c|c|c|c|c|}
\hline \multirow[t]{2}{*}{ VARIABLE } & \multirow{2}{*}{$\begin{array}{c}\text { DIAGNOSIS } \\
\text { NATIONALITY }\end{array}$} & \multicolumn{2}{|c|}{$\mathrm{HIV+}$} & \multicolumn{2}{|c|}{ CANCER } & \multicolumn{2}{|c|}{ NORMAL } & \multicolumn{2}{|c|}{ TOTAL } \\
\hline & & Mean & SD & Mean & SD & Mean & SD & Mean & SD \\
\hline TOTAL & & 9.07 & 5.46 & 9.33 & 4.52 & 5.50 & 5.94 & 7.97 & 5.59 \\
\hline \multicolumn{10}{|c|}{ " $\mathrm{t}$ " scores comparing the different subgroups on anger } \\
\hline \multicolumn{4}{|c|}{ Diagnosis } & \multicolumn{6}{|c|}{ "t"scores } \\
\hline \multicolumn{4}{|c|}{ HIV and Normals individuals } & \multicolumn{6}{|c|}{$3.42 * *$} \\
\hline \multicolumn{4}{|c|}{ Cancer and HIV individuals } & \multicolumn{6}{|c|}{$-0.29 \mathrm{NS}$} \\
\hline \multicolumn{4}{|c|}{ Cancer and Normals individuals } & \multicolumn{6}{|c|}{$3.98 * *$} \\
\hline
\end{tabular}


Looking at the table we see that cancer patients had highest anxiety followed by HIV seropositive individuals and with the least being in normal individuals. The difference between HIV and normal individuals was significant. The difference between HIV and Cancer was not significant $(t=-0.29)$. For both nations the lowest anxiety was reported in normal individuals. Thus the hypothesis that there will be significant differences on anxiety dimensions between HIV, Cancer and normal individuals in India and Zambia is accepted.

\section{Correlations between physical illness behavior [Somatic symptoms] and anxiety}

Hypothesis 2 stated that physical Illness behavior is positively correlated to anxiety. In order to carry out the investigation, the symptoms questionnaire ${ }^{1}$ was administered and the Pearson coefficient of correlation was computed. Physical illness behavior implies somatic symptoms which in the present study are indicators of physical illnesses such as head pains, cramps, muscle pains, upset bowels, nausea, weak arms and legs.

Table 9: Correlation between the level of physical illness behavior [somatic symptoms] and anxiety

\begin{tabular}{|c|c|c|}
\hline SI No & $\begin{array}{c}\text { Factors correlated to } \\
\text { Somatic symptoms }\end{array}$ & Correlation Coefficient \\
\hline 1. & Anxiety & $0.562^{* *}$ \\
\hline
\end{tabular}

Physical illness behaviour implies somatic symptoms which in the present study are indicators of physical illnesses such as head pains, cramps, muscle pains, upset bowels, nausea, weak arms and legs.

Anxiety: From table 2, it is clear that anxiety is positively and significantly correlated with physical illness behavior or somatic symptoms. Physical illness-behavior shows highest correlation $(0.562)$ to anxiety. This correlations imply that high level of emotions (anxiety) and physical illness behaviour seem to co- exist.

\section{Discussion}

The best vantage point to understand behaviour is from the internal frame of reference of the "individual himself",

The findings of the present study reveals that consistent and systematic difference exist between
HIV seropositive individuals and individual from the normative population with regard to their anxiety. These rates are similar to the rates reported in HIV literature for asymptomatic HIV+ men according to research findings ${ }^{9},{ }^{10}$ when they compared the rates of anxiety reported in the cancer literature and to the rates reported in medical clinics. This suggested that AIDS/HIV is not associated with a specific anxiety response. These findings are of clinical significance, highlighting the fact that persistent anxiety (e.g., feeling keyed up, restless, or worried) is not a normative response to advanced HIV illness. The importance of identifying and treating those who receive care from general medical providers with comboid anxiety disorders is underscored ${ }^{11}$. They report a substantial difference in quality of life between those with hypertension or diabetes with or without anxiety symptoms.

Interpretations of anxiety symptoms prevalence and comparison with other studies is complicated by the fact that the diagnostic nomenclature and measure have changed over the past few decades. For example, a diagnosis of generalized anxiety in DSM-II required a duration of 1 month of symptoms, whereas 6 months of symptoms and impairment in daily functioning are required by DSM-IV. Therefore it can be argued that the fact that criteria for anxiety disorders are more stringent than earlier versions highlights the importance of measuring subsyndromal anxiety symptoms that may still warrant clinical attention and intervention.

Cancer patients scored highest followed by HIV+ individuals and individuals from the normative population being the least. This result is in agreement with those ${ }^{12,13}$ when they argued that the fact that physical manifestations of HIV are more related to distress than laboratory markers is consistent with the findings of the studies with less ill populations as well as research on HIV and depression. This assertion is also in agreement with the findings ${ }^{14}$ in their study when they alluded to the fact that somatic complaints relate to psychological disturbance in less ill populations of asymptomatic homosexual men. Therefore the present study is in agreement with the view that this finding underscores the psychological importance of managing fatigue and HIV symptoms.

Basically, the individuals from the normative population are not only aware of the risk involved in life by various personal and social factors, but they 
also know that life may provide a mixed experience to everyone. One cannot lead a purposeful life without commitment, values and reality-orientation. Hence, come what may, they stand by a special life style which gives them lower levels of anxiety. On the other hand if an HIV+ individual does not adopt adaptive and active copying strategies to overcome his distress, the progression of their circumstances, this will create a state of diseqilibrium leading to the experience of dissatisfaction, anxiety and disorientation in life. Long-term survivors of HIV infection do not fall under this category because they do not resort to the negative methods of destroying themselves e.g., self-rumination.

The association of physical manifestations of HIV and anxiety may be understood two ways: 1) there is a bidirectional relationship between anxiety and physical distress (and what that may signify emotionally), or 2) there is an overlap between symptoms used to measure anxiety and physical symptoms themselves. Findings of the present study are maintained even when somatic items from the anxiety scales were eliminated, suggesting that physical symptoms, limitations, or fatigue may contribute to anxiety and tension.

Ruzindaza's review revealed that tension can be dealt with rationally by empting one's mind of all thoughts that bother him ${ }^{15}$. This enables a person to have inner power to fight against an affliction and have inner peace. The life of inner peace is the easiest and healthiest type of existence because this harmony of the mind overflows into the functions of the body while a disturbed mind, on the other hand, is a sick mind and it can easily corrupt the body. A great number of patients have nothing wrong with them, save their thoughts. The character of an individual's thoughts is what determines the pace at which he or she lives. Whenever the mind wanders from one hellish idea to another, a person becomes impatient and this kind of mood produces toxic poisons in the body and creates a sort of emotional disquiet which affects the individual physically. Solomon et al in their study revealed that life stressors have been implicated in the faster progression from HIV positive ${ }^{16}$. Koopman et al in a study found that two obvious stress related mechanisms responsible for deteriorating the immune system and for expediting the progression of HIV into AIDS are (a) the production of cortisol which suppresses the natural killer cells and (b) excess adrenaline which blocks macrophage activation and accelerates HIV replication ${ }^{7}$.

Another possible mechanism by which stress leads to faster disease progression in HIV disease is by reactivation of latent viruses which will patently have a harmful effect on HIV-infection.

Enhancement of well-being in individuals infected with HIV which continues to spread around the world causing nearly 16,000 new infections a day in the world, has posed a great challenge to the field of psychology. A cross cultural study on dimensions and enhancement of well-being in HIV+ individuals is important because it enables the researcher to surmise what individuals infected with HIV think and feel and how their lifestyles can be improved so that disability free years of healthy living can be increased. The significance of enhancing the well-being of HIV seropositive individuals is to assist them lead a healthy life of quality for many years so that at least, they may execute some of their responsibilities and ambitions.

Research studies have shown that increased life span in HIV seropositive individuals has been accompanied by the discovery of effective anti retroviral drugs. However what is really important is not only how long a person can live but how well they live. Since the quality of life and well-being of HIV seropositive individuals depends on how well they live upon learning about their seropositivity status, it is essential to add life to years through enhancement of wellbeing and not just years to life.

A close and detailed observation of research on wellbeing in individuals infected with HIV suggests its multifaceted nature and it is too vast, exhaustive and voluminous for an in-depth presentation. The present study examines the interaction among HIV seropositive individuals, cancer patients and individuals from the normative population on dimensions of well-being, for future integration of these constructs.

For both Zambia and India, it was found that the biggest number of individuals who experienced tension most of the time were HIV seropositive individuals followed by cancer patients and individuals from the normative population.

The finding that most HIV seropositive individuals experienced a life of tension is normal but has far 
reaching implication as was reviewed by Ruzindaza, when his study indicated that an individual's inner power to fight the illness or infection comes from a quiet mind. According to him, the essence of the secret of acquiring serenity of mind lies in a change of mental attitude because a quiet mind builds a "strong basis" which fills an individual with mental energy to see himself through hard situations. He further proposed that the life of inner peace is the easiest and healthiest type of existence because this harmony of the mind overflows into the functions of the body while a disturbed mind, on the other hand, is a sick mind and it can easily corrupt the body. To emphasize this, he points to many physicians who state that a great number of their patients have nothing wrong with them, save their thoughts. He thus concluded that the character of an individual's thoughts is what determines the pace at which he or she lives. Whenever his or her mind wanders from one hellish idea to another, they become impatient and this kind of mood produces toxic poisons in the body and creates a sort of emotional disquiet which affects the individual physically. It is therefore suggested that individuals infected with HIV need to learn how to empty their mind of all thoughts that bother them, such as offences, regrets, anger, hatred, jealous, malice etc... Obviously, they cannot move around with an empty mind, but they can fill their mind with thoughts which are more peaceful and constructive. This may surely seem to be an over-simplication of a big problem. But the mere fact that man can consciously make an effort to put unpleasant memories out of the mind and retain peaceful ones, means that seropositive individuals can use the same mechanism to do so. It is important for significant others of seropositive individuals to know their worries. They should show willingness to share these worries and where possible find a way of comforting the individuals and resolving their worries. This argument was empirically verified by Taylor et al when his study revealed that the effect of stress on our immune system may be less for people who have effective ways of dealing with stressors than for those who do not ${ }^{18}$. It was thus concluded that optimism, regular exercises, and feelings of control over stressful events are associated with reduced suppression of our immune system under stress.

Tension or distress in HIV seropositive individuals, cancer patients or individuals from the normative population is the body and mind's response to any pressure that disrupts their normal balance. The biggest number of individuals who experienced distress/tension most of the time was HIV seropositive individuals followed by cancer patients and individuals from the normative population. Distress occurred in most HIV seropositive individuals because their perceptions of events surrounding their infection do not meet their expectations and they do not manage their reaction to the disappointment. As a result their unmanaged reaction expresses itself as tension, strain or frustration, throwing off their physiological and psychological equilibrium. If their equilibrium is disturbed for long, the distress becomes disabling. They would begin to feel emotionally shut down, and eventually get sick.

From the aforementioned results, it is clear that anxiety is positively and significantly correlated with physical illness behavior or somatic symptoms. These correlations do not imply that physical illness behavior causes anxiety or otherwise but that high level of anxiety and physical illness behavior seem to co- exist. Certain features of the available research on implication of anxiety on HIV seropositive and cancer patients state that anxiety can be due to certain unmet emotional needs and/or psychological stress which act as barriers. Emotions are the bridge between the mind and the body. Peptides are the physical correlates of emotion; they are the carriers of information between the brain and body, body and brain. These peptides enable every system of the body to be in a constant state of dialogue. This includes the immune system and nervous system. Every change in our physiological state is mirrored by a shift in our emotional state, and every change in our emotional state is mirrored by a change in our physiological state. Unhappy emotions generate disease-promoting peptides.

Cancer patients and HIV seropositive individuals reported higher levels of anxiety than normal individuals. This implies that cancer patients and HIV seropositive individuals need to take more precautions against anxiety than individuals from the normative population. This is so because as is the case with fear, anxiety has been associated with a host of deadly conditions including irritable bowel syndrome, ulcers, headaches, skin disorders such as psoriasis, eczema and stress and decreased immune response, which can open up a person to even more serious illness.

Therefore the hypothesis that there will be significant differences on anxiety dimensions between HIV, cancer and normal individuals in India and Zambia is accepted. 


\section{CONCLUSION}

The upshot of the findings leads to the following conclusions: The normative population have lesser levels of anxiety than HIV+ individuals and cancer patients. There is no significant difference between anxiety in HIV+ individuals and cancer patients. Therefore illness makes a difference. Lastly physical illness behavior is positively correlated with anxiety. This implies that physical illness behavior [somatic symptoms] co-exist with anxiety. Therefore it's likely HIV positive individuals who have higher levels of anxiety will be more prone to somatic illness. Hence it can be argued that probably anxiety might be one of the core factors responsible for the quick progression of HIV into AIDS.

In summary, it can be concluded that even mild levels of anxiety are associated with fatigue, physical limitations, and more HIV symptoms. Therfore the present study supports the assertion by Margret et al that the ever-changing landscape of HIV medical treatment with its inherent uncertainties, clinical attention to anxiety is imperative as is continued as is continued research on the milder physical manifestations of HIV disease ${ }^{19}$.

\section{REFERENCES}

1. Kellner, R. (1986) Somatization and Hypochodriasis. Praeger-Greenwood, New York.

2. WHO (1976). Health aspects of Human Rights, World Health Organization, Geneva

3. Linn M.W., Linn S.B and Jensen J. (1984) Stressful Events, Dysphoric Mood, and Immune Responsiveness. Psychological Reports 54:219222

4. Dixon, $\mathrm{P}$ (1994). The Truth about AIDS; England: Kingsway Publications

5. Grant I. and Atkinson, J.H. (1995) Natural history of neuropsychiatric manifestations of HIV disease. In: Psychiatric Manifestations of HIV Disease. Psychiatric Clinics of North America 17, 17-33.

6. Spielberger.C and J. Sarason (1972), Stress and anxiety (Volume 2). New York: Wiley.

7. Smith Raymond. A. (2001) Social, Political, Cultural, and Scientific record of the HIV epidemic. Encyclopedia of AIDS. Penguin books. New York
8. Rogers, Carl (1951). A Theory of Therapy, Personality and Interpersonal Relationships as Developed in the Client-centered Framework. In (ed.) S. Koch (1963), Psychology: A study of a Science. Volume 3: Formulations of the person and the Social Context. New York: McGraw Hill.

9. Perkins DO, Stern RA, Golden RN, et al: Mood disorders in HIV infection: prevalence and risk factors in a nonepicenter of the AIDS epidemic. Am J psychiatry 1994; 151:233-236.

10. Rosenberger PH, Bornstein RA, nasrallah HA, et al: Psychopathology in human immunodeficiency virus infection: lifetime and current assessment. Compr Psychiatry $1993 ; 34 ; 150-158$

11. Sherbourne CD, Wells, KB, Meredith LS, et al: Comorbid anxiety disorder and the functioning and wellbeing of chronically ill patients of general medical providers. Arch gen psychiatry 1996; 53:889-895

12. Lipsitz JD, Williams JBW, Rabkin JG, et al: Psychopathology in male and female intravenous drug users with and without HIV. Am J Psychiatry 1994; 151:1662-1668

13. Fell M, Newman S, Herns M, et al: Mood and psychiatric disturbance in HIV and AIDS: changes over time. Br J Psychiatry 1993; 162:604-610

14. Griffin KW, Rabkin JG, Remien RR, et al: Disease severity, physical limitations and depression in HIV-infected men. J Psychosom Res 1998; 44:219-227

15. Ruzindaza Casimir (2002) Living positively with AIDS: An African. Experience Nairobi, Kenya: Paulines Publications Africa.

16. Solomon G.F, Ironson. G. H, and Balbin. E..G. (2000) Psychoneuroimmunology and HIV/ AIDS. Ann N Y Acad Sci; 917: 500-4.

17. Koopman C, Gole-felton C, Marouf F, Butler, Field L D, Gill M, Chen, X H Israelski D, and Spiegel D (2000) Relationships of perceived stress to coping, attachment and social support among HIV-positive persons. AIDS Care 2000; 12 (5): 663-72.

18. Taylor DN (1995), Effects of a behavioral stressmanagement program on anxiety, mood, selfesteem, and T-cell count in HIV positive men. Psychol Rep 76(2):451-457

19. Margret C, Kathy., Judith G., (1999) et al: In Morrison, J.M. Petitto, T et al (2002). Depression and anxiety disorders in women with HIV infection. The American Journal. May $1 ; 159$. 